\section{RELATION BETWEEN HEMODYNAMIC BEHAVIOR AND OCCURRENCE OF EARLY STENOTIC FAILURE OF BIOPROSTHESES \\ To the Editor:}

In the May issue of the Journal, Jamieson and Fradet $^{1}$ comment on a recent Brief Communication by Lawton and colleagues ${ }^{2}$ in which 4 cases of early failure of the Mosaic (Medtronic Inc, Minneapolis, Minn) porcine bioprosthesis are described, with development of severe valve stenosis necessitating replacement. In their letter, Jamieson and Fradet question the diagnosis of early structural valve degeneration (SVD) in these explants, stating that the valves reported by Lawton and colleagues were either thrombosed or covered by pannus.

We recently performed long-term clinical and echocardiographic followup in a series of 564 aortic bioprostheses (among which 152 were Mosaic valves) with the emphasis on studying the occurrence of structural valve deterioration as determined by echocardiography. ${ }^{3}$ We demonstrated a link between the presence of prosthesis-patient mismatch (PPM) defined as an indexed effective orifice area $\left(\mathrm{EOAi}, \mathrm{cm}^{2} / \mathrm{m}^{2}\right)$ less than 0.85 and the occurrence of early, stenotic-type $\mathrm{SVD}^{3}$ with elevated transvalvular gradients. We showed that patients with PPM are at risk for stenotic-type SVD, starting to occur from 3 to 4 years after implantation. In Lawton and colleagues, ${ }^{2}$ study, 3 of the 4 cases presented had an EOAi less

\footnotetext{
The Editor welcomes submissions for possible publication in the Letters to the Editor section that consist of commentary on an article published in the Journal or other relevant issues. Authors should: - Include no more than 500 words of text, three authors, and five references. - Type with double-spacing - See http://jtcs.ctsnetjournals.org/misc/ifora.shtml for detailed submission instructions. - Submit the letter electronically via jtcvs.editorialmanager.com. Letters commenting on an article published in the JTCVS will be considered if they are received within 6 weeks of the time the article was published. Authors of the article being commented on will be given an opportunity of offer a timely response (2weeks) to the letter. Authors of letters will be notified that the letter has been received. Unpublished letters cannot be returned.
}

than 0.85 and therefore had moderate PPM. The remaining patient had an EOAi of 0.89, which is borderline. The observed early dysfunction in these valves cannot be ignored, given the reported transvalvular gradients and effective orifice areas before their explantation. ${ }^{2}$ Lawton and colleagues have made a correct observation of 4 early, stenotic-type valve failures in patients with moderate PPM. It might still be that both pannus and thrombus were present in these valves, and that these elements were (partially) responsible for the pathologic hemodynamic behavior. But what causes such an early extensive pannus formation or early thrombotic changes at the surface of an aortic bioprosthesis? As stated by Carpentier ${ }^{4}$ in his editorial on our article, a relation between disturbed or turbulent transvalvular flow (as is the case when PPM is present) and bioprosthetic tissue failure has been suspected before but was never demonstrated. Banbury and colleagues ${ }^{5}$ noted a tendency for smaller bioprostheses to fail earlier, but they did not observe statistical significance in their analysis.

In our series, none of the implanted Mosaic valves has been explanted yet, but 7 of the 152 Mosaic valves have met our (echocardiography-based) criteria for stenotic-type SVD on followup echocardiography. The earliest was already observed after 2.5 years after implantation. Six of these patients had moderate PPM (EOAi range $0.66-0.82$ ), and the remaining patient had an EOA index of 0.88. PPM might not be harmful for the patient, but for the valve....

Bart Meuris, $M D, P h D$ Willem Flameng, $M D, P h D$ Department of Cardiovascular Diseases

Katholieke Universiteit Leuven Leuven, Belgium

\section{References}

1. Jamieson W, Fradet G. Aortic bioprosthesis-avoid obstructive properties due to thrombosis as altered durability due to structural valve deterioration. J Thorac Cardiovasc Surg. 2010;139:1354.
2. Lawton J, Moazami N, Pasque M, Moon M, Damiano R Jr. Early stenosis of Medtronic Mosaic porcine valves in the aortic position. $J$ Thorac Cardiovasc Surg. 2009;137:1556-7.

3. Flameng W, Herregods MC, Vercalsteren M, Herijgers P, Bogaerts K, Meuris B. Prosthesis-patient mismatch predicts structural valve degeneration in bioprosthetic heart valves. Circulation. 2010;121:2123-9.

4. Carpentier A. Hemodynamic factors affecting the fate of valvular bioprosthesis. Circulation. 2010; 121:2083-4.

5. Banbury M, Cosgrove D 3rd, White J, Blackstone E, Frater R, Okies J. Age and valve size effect on the long-term durability of the Carpentier-Edwards aortic pericardial bioprosthesis. Ann Thorac Surg. 2001;72:753-7.

doi:10.1016/j.jtcvs.2010.05.046

\section{Reply to the Editor:}

This communication is in response to the Letter to the Editor by Meuris and Flameng ${ }^{1}$ in response to our Letter to the Editor ${ }^{2}$ commenting on the brief communication by Lawton and colleagues. ${ }^{3}$ We identified that Lawton and colleagues misrepresented thrombosis and pannus (nonstructural dysfunction) as durability issues.

Meuris and Flameng ${ }^{1}$ are challenging our judgment and stating that Lawton and colleagues ${ }^{3}$ "have made a correct observation of four early, stenotic-type valve failures in patients with moderate PPM." We also stated " the radiographs were reported as part of the pathological reports, showing no mineralization of valve tissue in three and remnants of mineralization of host tissue on the sewing ring of the other prosthesis." We have reviewed all the documentation, including the radiographs, and stand with our original report.

Meuris and Flameng's concern is related to evidence recently published by Flameng and colleagues. ${ }^{1,4}$ These investigators evaluated the relationship of structural valve degeneration (SVD) and prosthesis-patient mismatch (PPM) (indexed effective orifice area [EOAi] to body surface area with known referenced effective orifice areas by prosthesis size). They found no relationship to survival for the level of EOAi, the same lack of influence as we found, ${ }^{5}$ but PPM less than 0.85 $\mathrm{cm}^{2} / \mathrm{m}^{2}$ is predictive of SVD (hazard 
ratio, $2.54 ; P=.006)$. Stenosis-type SVD developed early (3-4 years) in patients with PPM, whereas incompetenttype SVD developed late (up to 9 years) in patients without PPM. These authors hypothesized a causative relationship of SVD to PPM.

This report by Flameng and colleagues ${ }^{4}$ is the first to suggest a relationship of SVD to PPM (EOAi $<0.85 \mathrm{~cm}^{2} /$ $\mathrm{m}^{2}$ ). The other independent risk factor for early stenotic-type SVD was valve size of $21 \mathrm{~mm}$ or less. Valve size had no relationship to incompetent-type late SVD. Of the 564 patients, 152 had Medtronic Mosaic (Medtronic Inc, Minneapolis, MN) implants, and currently Flameng and colleagues ${ }^{4}$ have 7 patients being followed for early stenosis-type SVD. Flameng and colleagues ${ }^{4}$ conclude by stating "by avoiding PPM, the incidence of SVD should be reduced by $\geq 50 \%$."

We propose an alternative relationship that SVD developing in smaller size valve with reduced EOA may be identified earlier because of PPM advancing over time. The same hypothesis could be related to late incompetenttype SVD with degenerated changes not developing stenosis in larger valves, and consequently the development of leaflet tears and incompetence from late SVD causing problems of stress-related disease. In our reported study on AVR PPM, survival was not influenced by level of PPM, but bioprostheses was a predictive factor. ${ }^{5}$

The challenge to us that Lawton and colleagues, ${ }^{3}$ experience is SVD caused by moderate PPM is not acceptable, and further investigation is required. These valves had no documented bioprosthetic tissue degenerative changes and no mineralization of leaflet tissue on explant radiographs. In our experience, thrombosis developed in a small percentage of Medtronic Mosaic prostheses, possibly because of the abnormal coagulation profile.

We do not agree with Meuris and Flameng ${ }^{1}$ that Lawton and colleagues ${ }^{3}$ made the correct conclusion. We think our observations are correct, and these valves do not have SVD developing early from moderate PPM (in fact, we consider moderate PPM an EOAi of $>0.65-0.75 \mathrm{~cm}^{2} / \mathrm{m}^{2} ; 1$ of the cases should be classified as mild PPM, 2 cases should be classified just mild at $0.83 \mathrm{~cm}^{2} / \mathrm{m}^{2}$, and 1 case should be classified with no PPM at the time of implantation). We agree with Meuris and Flameng ${ }^{1}$ that this phenomenon requires further extensive investigation.

\section{W. R. Eric Jamieson, $M D$}

Guy J. Fradet, $M D$

Department of Surgery

University of British Columbia

Vancouver, British Columbia, Canada

\section{References}

1. Meuris B, Flameng W. Relation between hemodynamic behavior and occurrence of early stenotic failure of bioprostheses. J Thorac Cardiovasc Surg. 2010;140:1200.

2. Jamieson WRE, Fradet GJ. Aortic bioprosthesisavoid obstructive properties due to thrombosis as altered durability due to structural valve deterioration. J Thorac Cardiovasc Surg. 2010;139:1354.

3. Lawton J, Moazami N, Pasque M, Moon M, Damiano R Jr. Early stenosis of Medtronic Mosaic porcine valves in the aortic position. $J$ Thorac Cardiovasc Surg. 2009;137:1556-7.

4. Flameng W, Herregods MC, Vercalsteren M, Herijgers P, Bogaerts K, Meuris B. Prosthesispatient mismatch predicts structural valve degeneration in bioprosthetic heart valves. Circulation. 2010;121:2123-9.

5. Jamieson WRE, Ye J, Higgins J, Cheung A, Fradet GJ, Skarsgard P, et al. Effect of prosthesispatient mismatch on long-term survival with aortic valve replacement: assessment to 15 years. Ann Thorac Surg. 2010;89:51-9.

doi:10.1016/j.jtcvs.2010.07.043

\section{ANTICOAGULATION AFTER BIOPROSTHETIC AORTIC VALVE REPLACEMENT \\ To the Editor:}

We read with interest the article by ElBardissi and colleagues. ${ }^{1}$ We concur with their conclusions that early anticoagulation after isolated bioprosthetic aortic valve replacement in patients in sinus rhythm does not seem to reduce the risks of thromboembolism, except in high-risk groups, and that current recommendations should be revisited.
TABLE 1. Survey of United Kingdom consultant practice

\begin{tabular}{lc}
\hline Regimen & $\begin{array}{c}\text { Percent of } \\
\text { respondents }\end{array}$ \\
\hline Warfarin 3 mo & $15 \%$ \\
Warfarin > 3 mo & $0 \%$ \\
Aspirin 3 mo & $10 \%$ \\
Aspirin $>3$ mo & $48 \%$ \\
No medication & $10 \%$ \\
Other regimens & $17 \%$ \\
\hline
\end{tabular}

In a review of this subject, $\mathrm{we}^{2}$ learned that data are not uniform owing to the retrospective analysis of the majority of the articles. Only 2 are prospective randomized trials comparing an antiplatelet agent with vitamin $\mathrm{K}$ antagonist $^{3,4}$ and unclear anticoagulation and antithrombotic regimens. Furthermore, in many of the studies, the results of aortic and mitral valve replacements are combined. Despite this lack of evidence, guidelines for management of patients with valvular heart disease published by American College of Cardiology, American Heart Association, American College of Chest Physicians, and European Society of Cardiology all recommend the use of an anticoagulation regimen for the first 3 months after bioprosthetic aortic valve replacement. ElBardissi and colleagues ${ }^{1}$ have pointed out that practice differs widely from these recommendations. We carried out a survey of 194 United Kingdom consultant cardiac surgeons on antithrombotic therapy after bioprosthetic aortic valve replacement and received $171(88 \%)$ responses (Table 1). Because of the diverse results of this survey and insufficient evidence in the literature, like ElBardissi and colleagues, we believe that a randomized trial would be necessary.

We embarked on a feasibility phase of this trial. If a definitive randomized trial comparing aspirin with warfarin sodium monotherapy is considered, assuming a stroke rate of $1 \%$ to $5 \%$ per person-year, 1800 patients are required in each group. If a 3-armed trial comparing aspirin with warfarin or with no therapy is considered, approximately 5400 patients are required in 